\title{
Microchannel reactors for fast periodic operation: the catalytic dehydration of isopropanol
}

\author{
A. Rouge ${ }^{a}$, B. Spoetzl ${ }^{\mathrm{a}}$, K. Gebauer ${ }^{\mathrm{b}}$, R. Schenk ${ }^{\mathrm{b}}$, A. Renken ${ }^{\mathrm{a}, *}$ \\ ${ }^{a}$ Swiss Federal Institute of Technology, LGRC-EPFL, CH-1015 Lausanne, Switzerland \\ ${ }^{\mathrm{b}}$ Institut für Mikrotechnik Mainz (IMM) GmbH, D-55129 Mainz-Hechtsheim, Germany
}

\begin{abstract}
A microchannel reactor specially designed for periodic operation and a process to deposit a catalyst, $\gamma$-alumina, inside the reactor channels were developed. The hydrodynamics of the reactor was characterised. Although the flow in the microchannels is laminar, a uniform radial concentration profile and consequently a narrow residence time distribution were obtained. Depending on the manufacturing method the Bodenstein number was found to be $B o=u d / D_{m} \cong 70$. The catalytic coating had no influence on this distribution indicating a uniform deposition of the catalyst within the microchannels. As the inlet function was only slightly modified in the reactors, frequencies of up to $1 \mathrm{~Hz}$ could be imposed for periodic operation. The dehydration of isopropanol to propene was chosen as model reaction to study the dynamic behaviour of a microreactor under periodic concentration variations. The kinetics was firstly studied in a conventional fixed-bed reactor with the catalyst developed for the microreactor. Experimental results confirmed the theoretically predicted increase of the reactor performance under periodic operation exceeding the maximum obtainable performance under steady-state conditions. C 2001 Elsevier Science Ltd. All rights reserved.
\end{abstract}

Keywords: Microreactor; Periodic operation; Catalytic dehydration; Stop effect

\section{Introduction}

\subsection{Purpose of microreactor}

Unsteady state or periodic operation of continuously operated chemical reactors can lead to a considerable increase of selectivity and reactor performance compared to the optimal steady state (Silveston, Hudgins, \& Renken, 1995). For a given reaction the obtainable performance depends strongly on the amplitude and frequency of the imposed parameter variations. The optimal cycle period depends on the reaction kinetics and may be in the range of a fraction of a second up to hours. Due to the high inertia of conventional (macroscopic) reactors the attainable range of frequencies is rather low and in the order of $10^{-4}-10^{-2} \mathrm{~Hz}$.

Microreactors are much better suited for this type of operation at high frequencies. Indeed, very narrow residence time distributions (RTD) can be obtained in microchannels due to the very short radial diffusion times. This

* Corresponding author. allows high frequencies for the imposed concentration cycling and thus to get valuable informations on the kinetics or to reach the optimal operating conditions even for fast reactions. Since the volume of a single microchannel is small, typically $1-10 \mathrm{~mm}^{3}$, a useful microreactor contains hundreds or thousands of parallel channels. A careful design of the microreactor is necessary to avoid flow maldistributions between the channels, which would broaden the RTD. An international collaboration between different research groups was started to design and construct adequate microreactors and to investigate their behaviour with cycle periods as short as $1 \mathrm{~s}$ (Liauw et al., 1999).

This paper describes a microchannel reactor developed as part of this project and its hydrodynamic behaviour as part of this project. The geometry of the reactor is based on micro-heat exchangers described by Ehrfeld, Lutz, and Richter (1997).

\subsection{Model reaction}

For the catalytic dehydration of alcohols and deamination of amines to olefins on alumina or other 
amphoteric metal oxides, a drastic increase of the reaction rate is observed if the reactant feed is switched to zero.

This phenomenon has been named stop-effect (Koubek, Pasek, \& Ruzicka, 1980). Different models were proposed to describe it. Thullie and Renken (1991) discussed two of them. The model that best describes the experimental results obtained for the catalytic dehydration of ethanol (Golay, Wolfrath, Doepper, \& Renken, 1997) assumes the adsorption of the reactant A on two different sites $S_{1}$ and $S_{2}$, and a consecutive reaction involving an adsorbed intermediate $\left(\mathrm{AS}_{1}\right)$ and a free site $\mathrm{S}_{2}$. The reaction scheme is summarised as follows (A: alcohol; E: olefin; W: water):

$\mathrm{A}+\mathrm{S}_{1} \stackrel{k_{1} / k_{-1}}{\rightleftharpoons} \mathrm{AS}_{1}$

$\mathrm{A}+\mathrm{S}_{2} \stackrel{k_{2} / k_{-2}}{\rightleftharpoons} \mathrm{AS}_{2}$

$\mathrm{AS}_{1}+\mathrm{S}_{2} \stackrel{k_{3}}{\rightarrow} \mathrm{S}_{1}+\mathrm{S}_{2}+\mathrm{E}+\mathrm{W}$

Therefore, A adsorbed on $\mathrm{S}_{2}$ acts as an inhibitor. When the reactant feed is stopped, the reactant A desorbs rapidly from $\mathrm{S}_{2}$ and the concentration of free sites increases leading to a drastic increase of the reaction rate. Model simulations show that operating under periodic variation of the inlet concentration, the average reactorperformance can be considerably higher compared to the obtainable maximal steady-state value. Experimental results for the dehydration of ethanol on $\gamma$-alumina confirmed the predicted increase of the reactor performance (Golay, Doepper, \& Renken 1999).

With increasing rates of desorption from site $\mathrm{S}_{2}$, the stop-effect becomes more pronounced and the maximum reactor productivity under periodic operation is shifted to higher frequencies (Thullie \& Renken, 1991, 1993).

In the present study, the dehydration of isopropanol to propene on $\gamma$-alumina was chosen as the model reaction. Observation by Moravek (1992) let expect a marked influence of periodic operation on the reaction rates. Furthermore, the parallel reaction to ether is much slower than the reaction to propene, resulting in a propene selectivity higher than $80 \%$ (Fig. 1).

\subsection{Catalytic coating}

For some reactions, the walls of the microchannels can act directly as catalyst (Hönicke \& Wiessmeier, 1996). But, in general, the specific surface of the microreactor has to be expanded and modified. A common method is based on anodic oxidation of aluminium plates to generate porous alumina layers. The layer can then be impregnated with active compounds (Wiessmeier, Schubert, \& Hönicke, 1997). Alternatively, a porous oxide can be deposited in the channels by washcoating. This method is
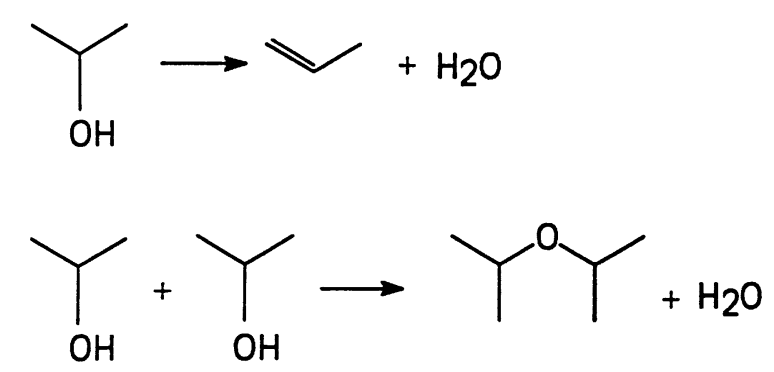

Fig. 1. Model reaction: dehydration of isopropanol over $\gamma$-alumina.

widely used in macroscopic systems (Brinker \& Scherer, 1990) and allows the use of any material as support for the manufacturing of the reactor.

Since the oxide obtained by anodic oxidation consists of $\alpha$-alumina, which can be only partially transformed in $\gamma$-alumina by heating to $600^{\circ} \mathrm{C}$ (Chen \& Hutchins, 1985) this method cannot be applied for the present study. Therefore, a washcoating method was developed to deposit the needed $\gamma-\mathrm{Al}_{2} \mathrm{O}_{3}$ layer in the microchannels of the stainless-steel reactor.

\section{Experimental}

\subsection{Microreactor design}

The microreactor consists of stacked plates (Fig. 2A) and behaves like a co-current or counter-current heat exchanger (Fig. 2B). The reactant mixture enters through an inlet tube, is distributed over the plates at various heights, then over the parallel channels and finally collected in an outlet device. The inlets and outlets of the reactor are placed on opposite sides of the stack of plates. Similarly, on each plate, the entrance and exit areas are triangular shaped with inlets and outlets on opposite sides of the channels array. These results in a uniform distribution of the fluid over the microchannels, which is indispensable for a narrow RTD. The proposed structure guarantees isothermal reaction conditions even for extremely fast exothermic or endothermic reactions. It also allows to impose rapid temperature variations in the reactor block.

The whole reactor, plates as well as the housing, is constructed on stainless steel. Each plate contains 34 quadrangular channels of $300 \mu \mathrm{m}$ width, $240 \mu \mathrm{m}$ depth and $20 \mathrm{~mm}$ length. The plates are micromachined by photoetching. For this technique the plates are first coated with a photoresist resin, exposed to UV light through a mask, developed and finally etched selectively in the developed areas. Then, the remaining protective resin is removed by dissolution in methanol. Plates with catalyst-coated channels and heat exchanger plates for heat removal are arranged alternatively. 


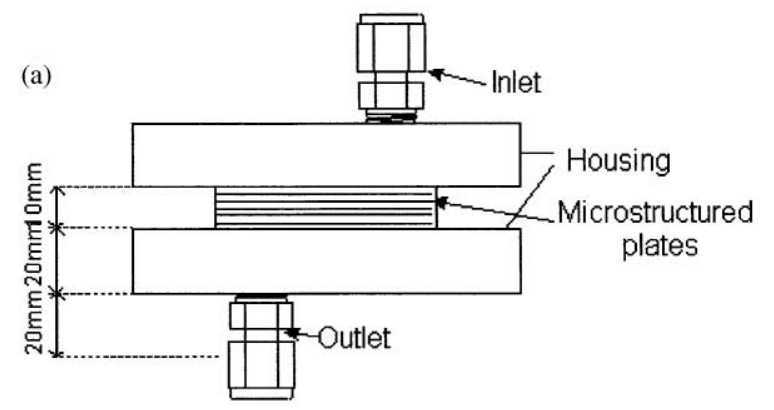

(b)

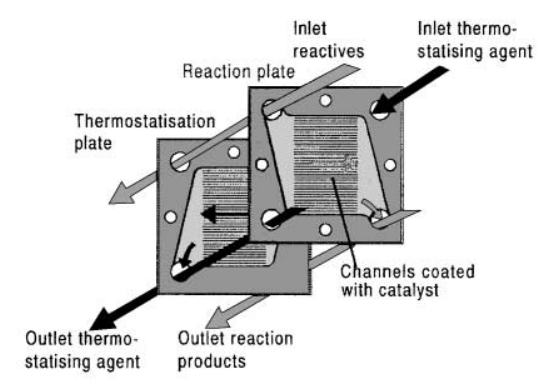

Fig. 2. A: side view of a microreactor, B: sketch of the fluid flows in the reactor.

In this work, three different reactors were assembled:

- Ten heat exchanger and 10 uncoated reaction plates were glued together. Reactor volume: $V_{R} \cong 0.9 \mathrm{~cm}^{3}$.

- Five plates of each type were glued together using coated reaction plates. Catalyst mass: $75 \mathrm{mg}$, $V_{R} \cong 0.5 \mathrm{~cm}^{3}$.

- Ten heat exchanger plates and 10 coated reaction plates were assembled with graphite joints. Catalyst mass: $120 \mathrm{mg}, V_{R} \cong 0.5 \mathrm{~cm}^{3}$.

For the experiments described here, the reactor block was heated from outside by an electrical tape. As the enthalpy of the model reaction is small and low reactant concentrations are applied, a homogeneous temperature distribution is obtained. This was confirmed by temperature measurements inside the reactor using a K-type thermocouple (Philips AG, Dietikon, Switzerland) introduced into the outlet tube.

\subsection{Catalyst preparation}

The initial solution for the washcoating can be either a colloidal suspension of boehmite in water or a solution of aluminium alkoxide (Brinker \& Scherer, 1990). By heating subsequently the deposited film to $450-500^{\circ} \mathrm{C}$ a layer of porous $\gamma$-alumina is obtained. During drying, cracks appear in thick films resulting in a detachment of the layer from the substrate. Therefore, this method is reported not to be satisfactory for films thicker than $2 \mu \mathrm{m}$ (Nass \& Schmidt, 1990; Harizanov \& Surtchev, 1997).
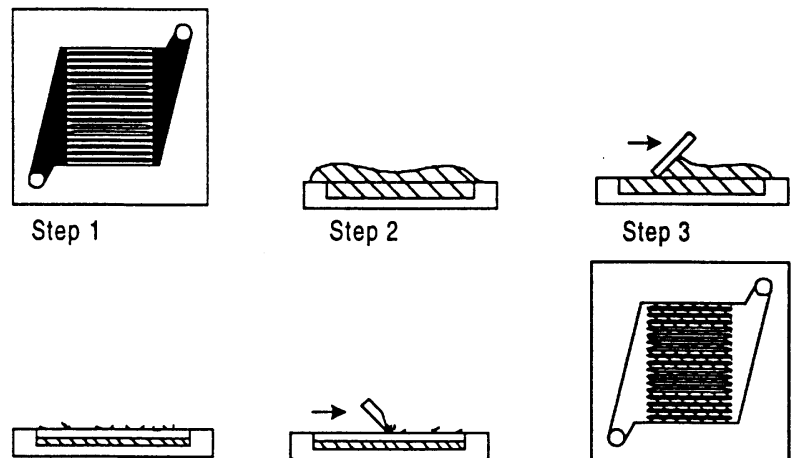

Step 4

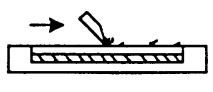

Step 5

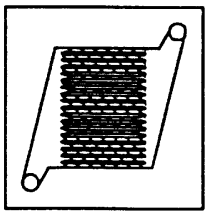

Step 6

Fig. 3. Process for the deposition of the catalyst in the microchannels: (1) Protecting the in and outlet chambers with a polymer film. (2) Depositing the suspension on the plate. (3) Wiping off any excess suspension. (4) Drying at room temperature. The layer shrinks. (5) Cleaning mechanically the upper surface of the plate. (6) Heating up to $500^{\circ} \mathrm{C}$ within $3 \mathrm{~h}$ in order to burn the polyvinyl alcohol and the protecting polymer film and dehydrate the boehmite to $\gamma$-alumina.

In order to obtain thicker films, $\gamma$-alumina powder was added to an aqueous suspension of boehmite, the boehmite acting as a binder for the particles (Dupin, 1984). In this way, considerable thicker films consisting of an agglomerate of particles instead of a homogeneous layer were obtained.

For the washcoating procedure, an aqueous suspension containing 15\% boehmite (HT100, Condea, Hamburg, Germany). $15 \% \quad \gamma-\mathrm{Al}_{2} \mathrm{O}_{3}$ (prepared by the dehydration of Boehmite at $500^{\circ} \mathrm{C}$ ), $1 \%$ acetic acid (purum, Fluka Chemie AG, Buchs, Switzerland) and 4\% polyvinylalcohol $M_{W}=49,000$, Fluka Chemie AG) was used. In order to ensure a homogeneous deposition in the channels and to maintain the entrance and exit chambers clean, a six-step procedure was used (Fig. 3). Each plate was weighed before and after the coating in order to determine the amount of catalyst deposited.

A part of the suspension was dried and calcinated separately under the same conditions as the plates in order to obtain $\gamma$-alumina powder with properties as similar as possible to those of the coating. This powder was sifted and particles with diameters of $0.1-0.35 \mathrm{~mm}$ were used for preliminary kinetic measurements in a conventional fixed-bed reactor. A specific surface area of $230 \mathrm{~m}^{2} / \mathrm{g}$ was determined by the BET method using a Sorptomatic 1990 (Carlo Erba) instrument. The pore size distribution of the catalyst is shown in Fig. 4.

\subsection{Fixed-bed reactor}

A quartz tube (internal diameter: $10 \mathrm{~mm}$, length: $200 \mathrm{~mm}$ ) packed with a small quantity of catalyst powder was used for kinetic experiments. The remaining volume was filled with quartz beads. The tube was heated from 


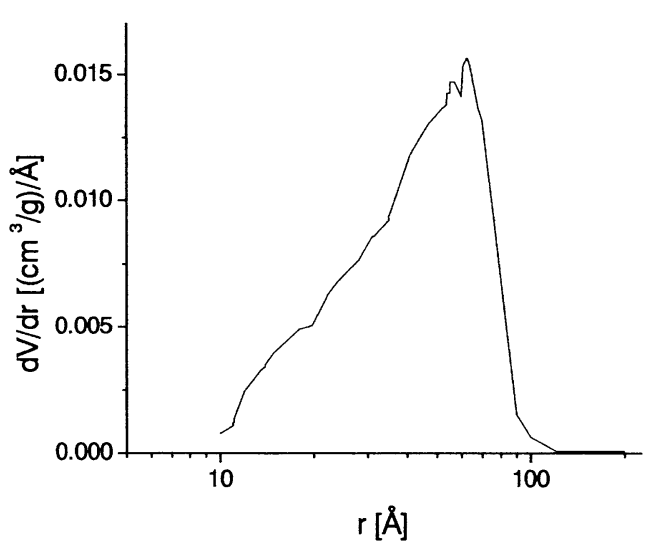

Fig. 4. Pore size distribution of the $\gamma$-alumina powder prepared for the fixed-bed reactor.

outside using an electrical tape. The temperature in the fixed bed was measured with a K-type thermocouple (Philips AG).

\subsection{Experimental set-up}

The used installation consists of two feed sections, the microreactor, and a quadrupole mass spectrometer (QMS 400, Balzers, Balzers, Liechtenstein) (Fig. 5). The installation allows switching between inert gas $\mathrm{N}_{2}$ ( $>99.95 \%$, Carbagaz, Lausanne, Switzerland) or a $\mathrm{N}_{2} / \mathrm{H}_{2} \mathrm{O}$ mixture and the reactant feed consisting of an isopropanol ( $>99.5$, Fluka Chemie AG) nitrogen mixture. All the gases were supplied through mass flow controllers (Bronkhorst High-Tech B.V., Ruurlo, The Netherlands). The liquids are dosed by bubbling nitrogen through bubble columns.

Switching of the four-way valve at the reactor inlet is controlled by a timer, permitting cycling periods between 0.001 and $10 \mathrm{~Hz}$. Pressure changes in the reactor are minimised by adjusting the pressure in the reactor and the ventilation line by means of needle valves.

The intensities of various fragments are measured continuously with the mass spectrometer (MS). These intensities are converted into concentrations using one-point calibrations. Since the response factor of the mass spectrometer change with time, the calibrations are repeated daily.

\subsection{Hydrodynamic measurements}

The three reactors used were characterised by RTD measurements. Argon (1-2 vol\% in $\mathrm{N}_{2}$ ) was used as tracer. The concentration of argon was determined by mass spectroscopy every $30 \mathrm{~ms}$.

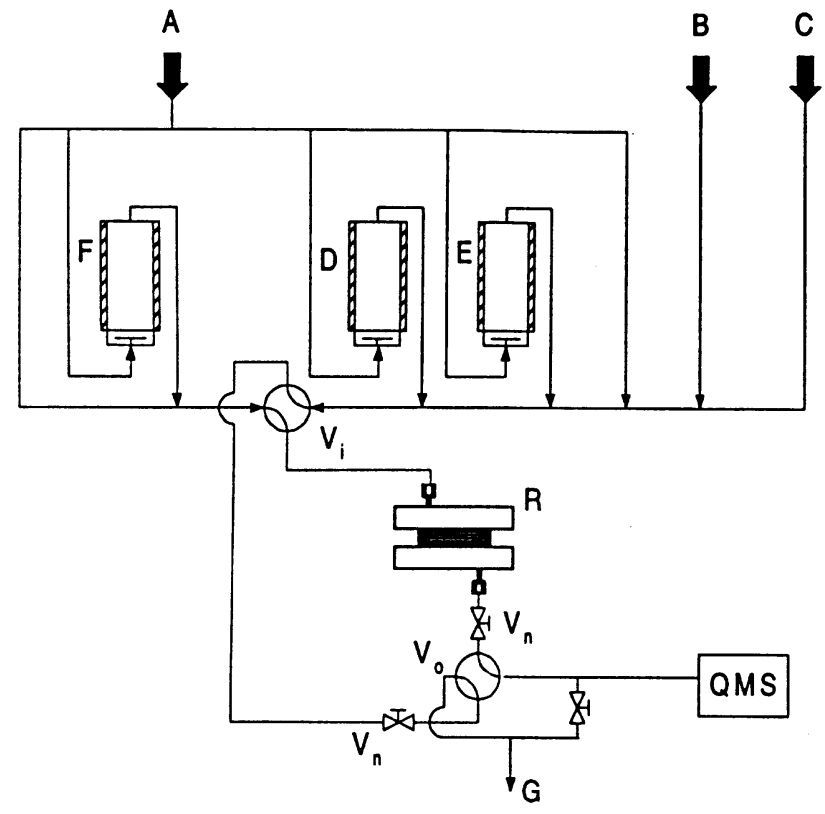

Fig. 5. Experimental set-up. Gas inlets: (A) $\mathrm{N}_{2}$; (B) $\mathrm{Ar}$; (C) $\mathrm{C}_{3} \mathrm{H}_{6}$; Thermostated bubble columns (saturators): (D) iPrOH; (E) ether; (F) water. $(\mathrm{G})$ hood; $(\mathrm{R})$ microreactor; $\left(\mathrm{V}_{\mathrm{I}}\right)$ four-way valve for concentration cycling; $\left(\mathrm{V}_{\mathrm{o}}\right)$ four-way valve for analyzing the reactor or the by-pass flow; $\left(V_{n}\right)$ needle valves for pressure adjusting; $(\mathrm{QMS})$ quadrupole mass spectrometer.

\subsection{Kinetic measurements}

Prior to each experiment, the reactor was heated to $400^{\circ} \mathrm{C}$ for $1 \mathrm{~h}$ to reactivate the catalyst. After cooling to $200^{\circ} \mathrm{C}$, the reaction was run stationary for $14 \mathrm{~h}$ in order to stabilise the catalyst activity. The concentrations of diisopropylether, isopropanol and propene were obtained measuring the intensities of the masses 87, 43 and 42 , respectively every $2 \mathrm{~s}$ with the MS. Quantitative determination of the water concentration was not possible, large amounts of background water being always present on the MS spectra.

Three types of transient experiments were effectuated in the fixed-bed reactor at $200^{\circ} \mathrm{C}$ by switching iP$\mathrm{rOH} /$ inert, inert/iPrOH and $\mathrm{irOH} / \mathrm{H}_{2} \mathrm{O}-\mathrm{N}_{2}$. The pressure was hold constant at $130 \mathrm{kPa}$ and the inlet concentrations were fixed to $\mathrm{C}_{\mathrm{iPrOH}, \text { in }}=0.86$ and $\mathrm{C}_{\mathrm{H}_{2} \mathrm{O}}=0.25 \mathrm{~mol} / \mathrm{m}^{3}(\mathrm{STP})$.

Periodic experiments were carried out in the microreactor with five coated reaction plates, glued together. During each periodic experiment the inlet concentration of $\mathrm{iPrOH}$ was varied according to a symmetric square wave function between 0 and $0.86 \mathrm{~mol} / \mathrm{m}^{3}$. Each experiment was repeated during $1 \mathrm{~h}$ for a given set of reaction parameters (cycle length and flow rate). This was sufficient to get cycle invariance between two successive periods. 


\section{Results and discussion}

\subsection{Hydrodynamics}

The age distributions for the experimental set-up with and without reactor were calculated from the outlet signal obtained when switching between a pure $\mathrm{N}_{2}$ feed and a feed containing Ar (Fig. 6). The dispersion in the experimental set-up, reactor excluded, is mainly caused by the MS. At low flow rates $(0.2-0.3 \mathrm{ml} / \mathrm{s})$ used for the RTD measurements the overall dispersion is almost due to the dispersion in other parts of the experimental set-up can be neglected.

The mean residence time in the microreactor, $\tau$, is calculated from the difference between the mean residence time in the set-up with, $\tau_{S M}$, and without microreactor, $\tau_{S}$.

$\tau=\tau_{S M}-\tau_{S}$

The dimensionless residence time distributions in the reactor are shown in Fig. 7 with:

$E(t / \tau)=E(t)_{S M} \tau$

According to Levenspiel (1972), the RTD function for tubular reactors with a small extend of dispersion can be described by

$E(t / \tau) \cong \frac{1}{2} \sqrt{\frac{B o}{\pi t / \tau}} \exp \left(-\frac{(1-t / \tau)^{2} B o}{4 t / \tau}\right)$

with $B o=u L / D_{\mathrm{ax}}$. The value of $B o$ has been optimised to obtain the best fit for the experimental data.

The obtained experimental residence time distributions show that the microreactor behaves almost like a plug flow reactor with $B o=70$ for the uncoated and coated glued reactor and $B o=33$ for the reactor with graphite joints.

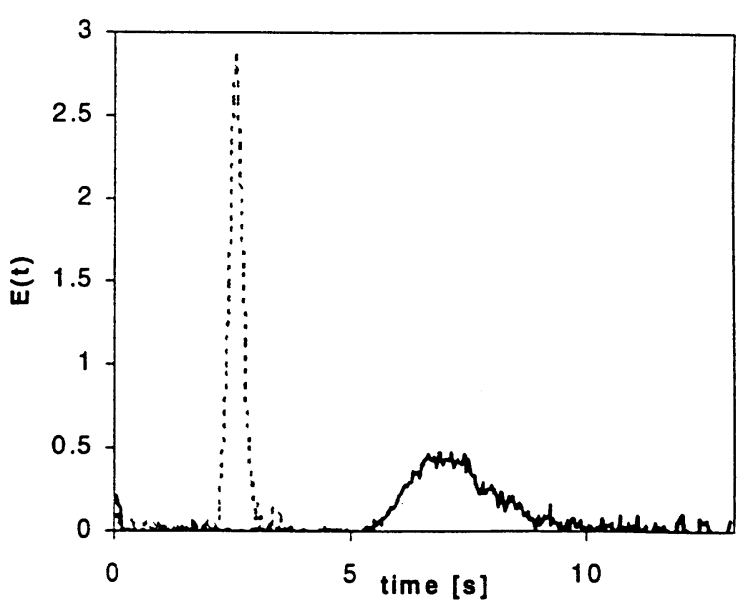

Fig. 6. Age distributions in the experimental setup; flow $0.2 \mathrm{ml} / \mathrm{s}$. without microreactor; ---, with microreactor (glued without coating).

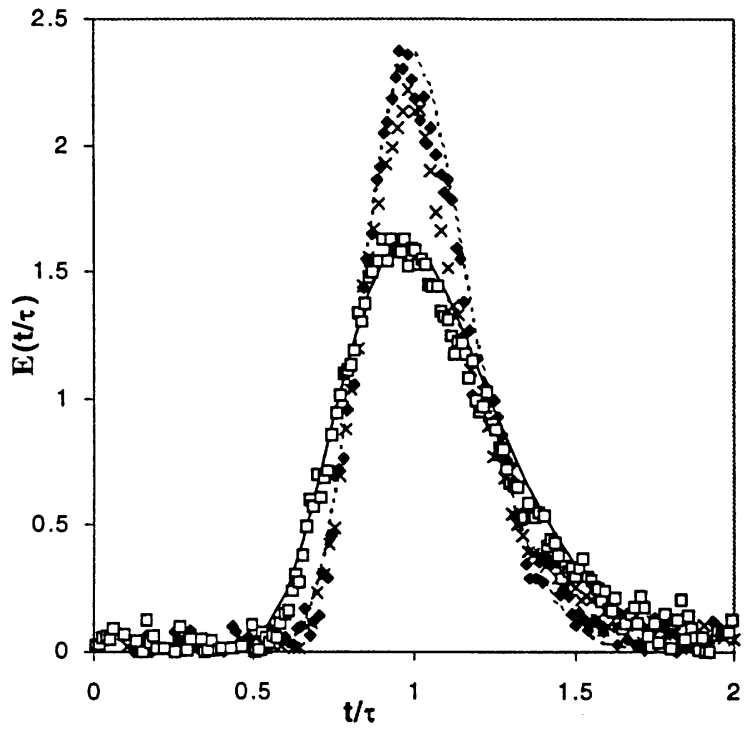

Fig. 7. Residence time distribution in different micro-reactors: $\bullet$ Glued reactor without coating; $\times$ glued reactor with coating; $\square$ reactor with graphite joints. Theoretical RTD curves for tubular reactors with: $B o=33 ;---, B o=70$.

The curves for the glued reactors on Fig. 7 clearly show that the catalytic coating has nearly no influence on the RTD. On the contrary, changes in the manufacturing method can have a dramatic influence on the width of the distribution. In the present case, the insertion of graphite joints introduces presumably small variations of the geometry that deteriorate the repartition of flow between different channels.

Based on the known response function of the mass spectrometer (Fig. 6) and the dispersion model the response of the system to arbitrary concentration variation at the reactor inlet can be estimated. The response is given by the convolution of three functions as indicated in Fig. 8. In Fig. 9 measured concentration variation curves for oscillations at $1 \mathrm{~Hz}$ and a residence time, of $\tau=0.54 \mathrm{~s}$ are compared with the predicted curves. The agreement between measured and calculated results is nearly perfect. The concentration profiles at the outlet of the reactor will be discussed further, using data calculated through a convolution of the inlet concentration function and the model RTD curve for the reactor.

The influence of the Bodenstein number and the residence time on the response curves at periodic operation are shown in Fig. 10. For short mean residence times compared to the length of period, the inlet square wave function is only slightly modified at the reactor outlet. With increasing mean residence time the square wave is finally transformed to a sinus like function. This transformation becomes more important with increasing dispersion.

We can thus conclude that a narrow residence time distribution is of crucial importance when the ratio cycle 

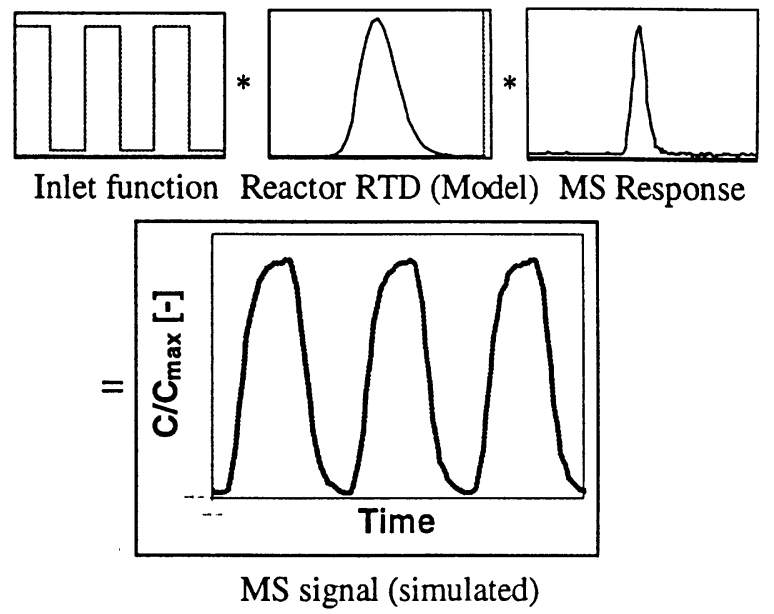

Fig. 8. Calculation method for the simulated MS signal: convolution of the forced inlet concentration, the reactor RTD (model, Fig. 7) and the MS response (measured, Fig. 6).

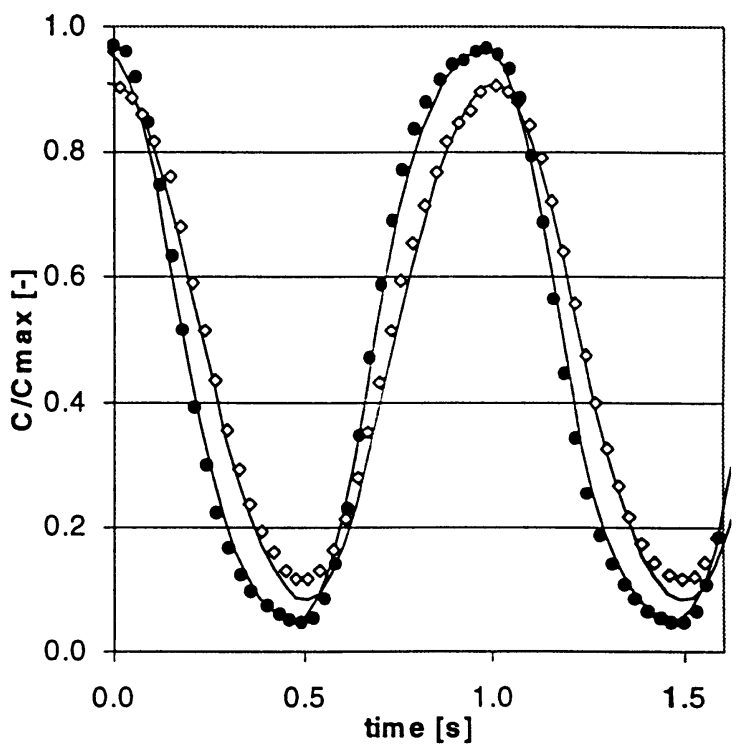

Fig. 9. Comparison between simulated and measured MS signal. Switching between inert feeds with 0 and $1 \% \mathrm{Ar}$ in $\mathrm{N}_{2}$. Frequency, $1 \mathrm{~Hz}, \tau=0.54 \mathrm{~s}: \bigcirc$, reactor with 10 uncoated plates, glued, $B o=70 ; \diamond$, reactor with 10 coated plates and graphite joints, $B o=33$; simulated curves.

period over residence time decreases. Even for reactors with $B o=70$ the length of the cycle period should correspond at least to $2 \tau$.

\subsection{Isopropanol dehydration}

Reaction in the fixed bed reactor. Transient experiments (steps $\mathrm{iPrOH} /$ inert, inert/iPrOH and $\mathrm{iPOH} / \mathrm{H}_{2} \mathrm{O}$ ) were performed in the fixed-bed reactor in order to elaborate a kinetic model and to determine the model parameters.
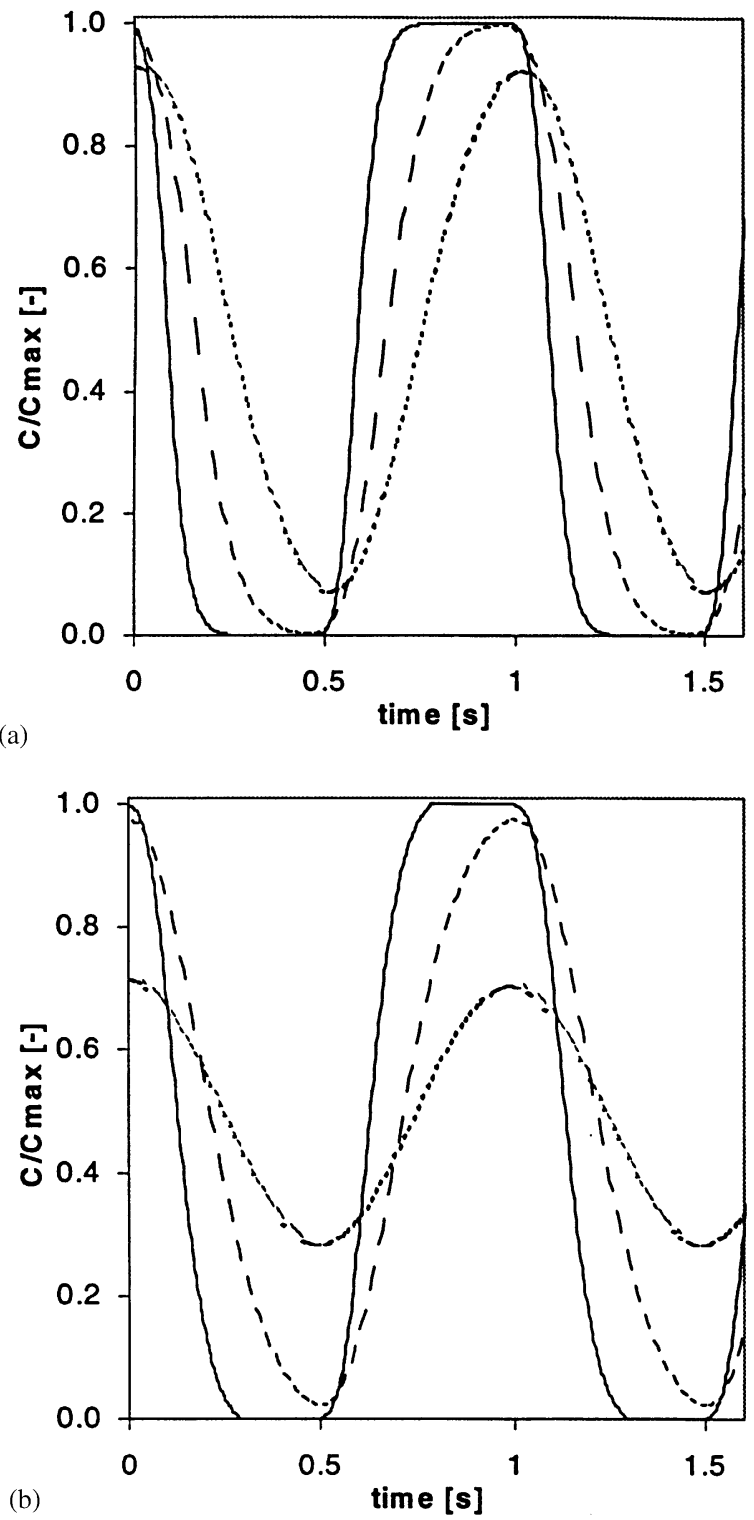

Fig. 10. Simulated response at the reactor outlet when switching between inert feeds with 0 and $1 \% \mathrm{Ar}$ in $\mathrm{N}_{2}$. Frequency $1 \mathrm{~Hz}$, reactor with $B o=70(\mathrm{~A})$ and $B o=33$ (B). $\tau:-, 0.27 \mathrm{~s} ;--, 0.54 \mathrm{~s} ;---, 1.08 \mathrm{~s}$.

After a switch $\mathrm{iPrOH} /$ inert (Fig. 11A), the concentration of propene increases sharply and passes through a maximum before falling to zero. At the same time the concentrations of the educt and the products fall quickly to zero after the reactant feed is stopped. After a switch inert/iPrOH (Fig. 11B) the propene concentration first begins to increase while $\mathrm{iPrOH}$ is adsorbed on the catalyst. During this first phase large amounts of water are measured, indicating that water is released during the adsorption process of iPrOH. After ca. $60 \mathrm{~s}$, the outlet concentration of $\mathrm{iPrOH}$ increases rapidly and the concentration of water falls back to a stationary value. Finally, after a switch iPrOH/water-inert (Fig. 11C), almost no transient increase of the propene concentration is 

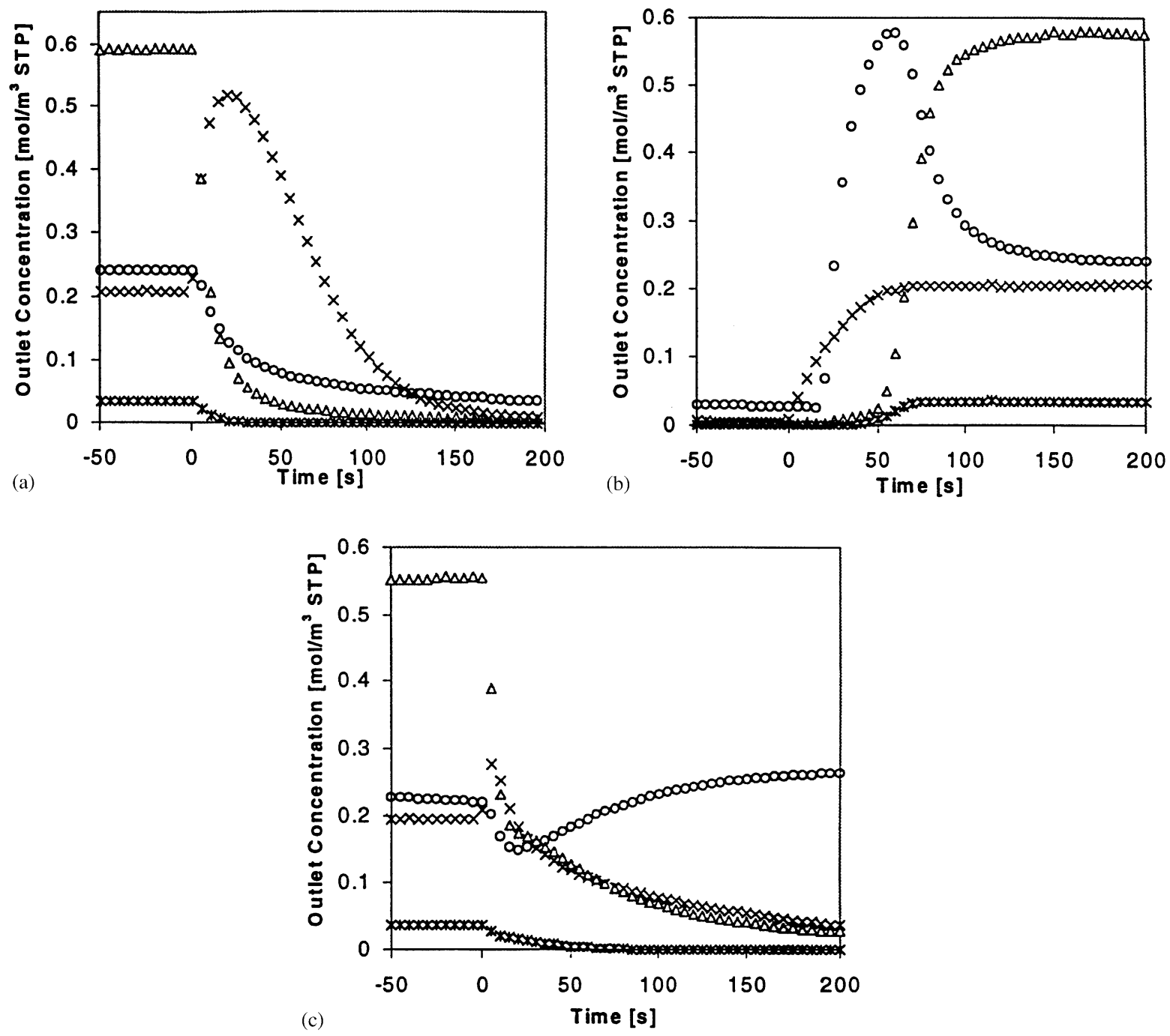

Fig. 11. Transient experiments in the fixed-bed reactor: catalyst mass $0.26 \mathrm{~g}, T=200^{\circ} \mathrm{C}, P=1.3 \mathrm{bar}, C_{\mathrm{iPrOH}}=0.86 \mathrm{~mol} / \mathrm{m}^{3} \mathrm{STP}, Q=3.33 \mathrm{ml} / \mathrm{s} \mathrm{STP}$; switches at $t=0 \mathrm{~s}$. A: switch $\mathrm{iPrOH} /$ inert; B: switch inert $/ \mathrm{iPrOH}$; $\mathrm{C}$ : switch $\mathrm{iPrOH} /$ water $\left(C_{\mathrm{H}_{2} \mathrm{O}}=0.25 \mathrm{~mol} / \mathrm{m}^{3} \mathrm{STP}\right)$. Experimental data: $\triangle$, isopropanol; $\times$, propene; $*$, ether; $\circ$, water (qualitative only).

observed and the $\mathrm{PrOH}$ decreases much slower than after the switch $\mathrm{iPrOH} /$ inert. It can be concluded that water expels iPrOH from the catalyst surface and simultaneously inhibits the formation of propene.

The kinetic model taken from the literature has been modified in order to take into account the described observations. First, since ether is observed during all the experiments, a reaction step has been added in the model. The ether formation is described, for simplicity, by a reaction between two molecules adsorbed on $S_{1}$ and $S_{2}$. Secondly, since water is released during the adsorption of $\mathrm{iPrOH}$ and can expel $\mathrm{iPrOH}$ from the $\mathrm{S}_{1}$ sites, the adsorption step on $\mathrm{S}_{1}$ has been replaced by an instantaneous adsorption equilibrium between $\mathrm{iPrOH}$ and water on these sites. Thirdly, water has also an inhibiting effect on the propene formation. This is described assuming a reversible adsorption of water on sites $\mathrm{S}_{2}$.
The last two modifications are consistent with the observations of Moravek (1992). Finally, the following reaction scheme is proposed $\left(\mathrm{A}\right.$ : $\mathrm{iPrOH} ; \mathrm{D}$ : $(\mathrm{iPr})_{2} \mathrm{O}$; E: $\mathrm{C}_{3} \mathrm{H}_{6} ; \mathrm{W}: \mathrm{H}_{2} \mathrm{O}$ ):

$$
\begin{aligned}
& \mathrm{A}+\mathrm{WS}_{1} \stackrel{K_{1}}{\leftrightarrow} \mathrm{AS}_{1}+\mathrm{W}, \quad \theta_{1} \frac{K_{1} \cdot C_{A}}{C_{W}+K_{1} \cdot C_{A}}, \\
& \mathrm{~A}+\mathrm{S}_{2} \stackrel{K_{2}}{\leftrightarrow} \mathrm{AS}_{2}, \quad \theta_{2}=\frac{K_{2} C_{A}}{1+K_{2} C_{A}+K_{2 W} \cdot \mathrm{C}_{W}}, \\
& \mathrm{~W}+\mathrm{S}_{2} \stackrel{K_{2 W}}{\leftrightarrow} \mathrm{WS}_{2}, \quad \theta_{2 W}=\frac{K_{2 W} C_{W}}{1+K_{2} C_{A}+K_{2 W} C_{W}}, \\
& \mathrm{AS}_{1}+\mathrm{S}_{2} \stackrel{k_{3}}{\leftrightarrow} \mathrm{E}+\mathrm{WS}_{1}+\mathrm{S}_{2}, \\
& R_{3}=k_{3} \theta 1\left(1-\theta_{2}-\theta_{2 W}\right), \\
& \mathrm{AS}_{1}+\mathrm{AS}_{2} \stackrel{k_{4}}{\leftrightarrow} \mathrm{D}+\mathrm{WS}_{1}+\mathrm{S}_{2}, \quad R_{4}=k_{4} \theta_{1} \theta_{2} .
\end{aligned}
$$




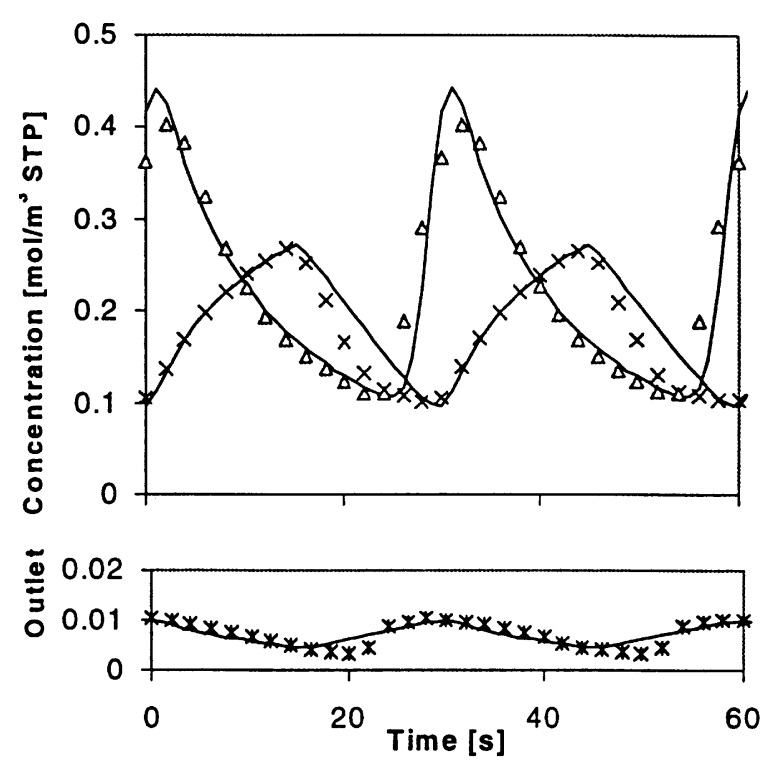

Fig. 12. Evolution of the outlet concentrations during a period. Microreactor with five plates, volume $\sim 0.5 \mathrm{~cm}^{3}$, catalyst mass $0.075 \mathrm{~g}, T 200^{\circ} \mathrm{C}, P 1.3 \mathrm{bar}$, split $0.5, t_{P} 30 \mathrm{~s}, C_{\text {iPrOH.mean }} 0.43 \mathrm{~mol} / \mathrm{m}^{3}$ STP, $\tau 0.175 \mathrm{~s} ; C_{\mathrm{iPrOH}}$ switches from $0.86 \mathrm{~mol} / \mathrm{m}^{3} \mathrm{STP}$ to 0 at $t=0 \mathrm{~s}$. Experimental data: $\triangle$, isopropanol; $\times$, propene: $*$, ether, model: lines.

$K_{i}$ are the different equilibrium constants, $k_{i}$ the rate constants, $\theta_{1}$ is the fraction of sites $S_{1}$ occupied by isopropanol, $\theta_{2}$ and $\theta_{2 w}$ are the fractions of sites $\mathrm{S}_{2}$ occupied by isopropanol and water respectively. Two further parameters, $Z_{1}$ and $Z_{2}$ (in $\mathrm{mol} / \mathrm{kg}$ catalyst), the densities of sites $S_{1}$ and $S_{2}$ have to be known in order to predict the dynamic behaviour of the catalyst. Different transient experiments are used in order to estimate the presented model parameters.

Model for the reaction in the microreactor. The dynamic behaviour of the microreactor is simulated using a reactor model combined with the kinetic model developed in separate experiences in the fixed-bed reactor. The following general equation allows to calculate the concentration of the reactants and products at any point in the reactor:

$\frac{\delta C_{i}}{\delta t}=R_{i}-\frac{\delta C_{l}}{\delta Z} \frac{1}{\tau}+\frac{\delta^{2} C_{i}}{\delta Z^{2}} \frac{1}{B o} \frac{1}{\tau}$.

$C_{i}$ and $R_{i}$ are the local concentration and the local reaction rate of component $i, Z$ is the adimensional axial coordinate in the reactor. The dispersion in the reactor is characterised by the Bodenstein number determined by RTD measurements.

Periodic operation of the microreactor. In Fig. 12 the concentrations of $\mathrm{PrOH}$, propene and ether as function of time for a cycle period of $30 \mathrm{~s}$ are given. The predicted curves, based on the separately developed reactor and kinetic models describe the dynamic behaviour of the microreactor quantitatively and will serve for the reactor optimisation.

\section{Conclusions}

A microreactor suitable for operation at fast concentration cycling was developed. Its hydrodynamics was characterised. The residence time distribution of the microreactor can be described correctly by the dispersion model. The extent of dispersion in the reactor is relatively small. The presence or absence of a catalytic coating of the microchannels has no influence on the residence time distribution.

The kinetics of the dehydration of isopropanol on $\gamma$-alumina under non-stationary conditions was studied in a fixed-bed reactor. Based on the experimental results a detailed kinetic scheme is proposed. The dehydration under periodic operation in the microreactor could be successfully described with this model.

Additional studies are needed to investigate precisely the causes of the observed axial dispersion in the microreactor and will lead to an optimised reactor design. Further model simulations are planned to study the influence of the operating conditions on the average productivity of the microreactor under periodic operation.

\section{Notation}

A reacting alcohol

Bo $\quad$ Bodenstein number $\left(=v L / D_{\mathrm{ax}}\right)$

$C_{i} \quad$ concentration of compound $i, \mathrm{~mol} / \mathrm{m}^{3}$ (STP)

D diisopropylether

$D_{\text {ax }} \quad$ axial diffusion coefficient, $\mathrm{m}^{2} / \mathrm{s}$

E olefin (propene)

$k_{i} \quad$ rate constant, $\mathrm{kg} / \mathrm{mol} \mathrm{s}$

$K_{i} \quad$ equilibrium constant, various units

$L \quad$ length (tubular reactor), $\mathrm{m}$

MS mass spectrometer

$\mathrm{P} \quad$ propene

$P \quad$ pressure, bar

RTD residence time distribution

$S_{i} \quad$ active site of type $i$

STP standard conditions $\left(25^{\circ} \mathrm{C}, 1\right.$ bar $)$

$t_{P} \quad$ cycle period, $\mathrm{s}$

$v \quad$ gas velocity, $\mathrm{m} / \mathrm{s}$

W water

$\mathrm{Z}$ axial coordinate in the reactor, normalized

$Z_{i} \quad$ concentration of $S_{i}$ on the catalyst, $\mathrm{mol} / \mathrm{kg}$

\section{Greek letters}

$\tau \quad$ residence time (in the microreactor when subscript missing) 


\section{Subscripts}

S experimental set-up without microreactor SM experimental set-up with microreactor

\section{Acknowledgements}

The authors gratefully acknowledge the help of P. Bowens and M. Staiger of the material science department at EPFL for their help in developing the coating procedure. They are grateful to the Swiss National Science Foundation and the "Bundesministerium für Forschung und Technologie" (Germany) for financial support.

\section{References}

Brinker, J., \& Scherer, G. W. (1990). Sol-Gel Science. Boston: Academic Press.

Chen, C. T., \& Hutchins, G. A. (1985). Crystalline anodic oxide growth on aluminium foil in an aqueous ammonium dihydrogen phosphate anodization electrolyte. Journal of Electrochemical Society, 132(7), $1567-1574$.

Dupin, T. (1984). Alumina Coating Compositions for Catalyst Supports and Process for their Formulation. Rhone Poulenc Specialites Chimiques, Courbevoie, France. US-Patent 4529718.

Ehrfeld, W., Lutz, W., \& Richter, Th. (1997). Verfahren zur Herstellung von Mikrowärmeaustauschern. Institut für Mikrotechnik Mainz. DE-Patent 19608824A1.

Golay, S., Doepper, R., \& Renken, A. (1999). Reactor performance enhancement under periodic operation for the ethanol dehydration over $\gamma$-alumina, a reaction with stop-effect. Chemical Engineering Science, 54, 4469-4474.
Golay, S., Wolfrath, O., Doepper, R., \& Renken, A. (1997). Model discrimination for reactions with stop-effect. In G. F. Froment, \& K. C. Waugh (Eds.) Dynamics of surface and reaction kinetics in heterogeneous catalysis. (vol. 109) (pp. 295-304) Amsterdam: Elsevier.

Harizanov, O. A., \& Surtchev, M. (1997). Glycerol treated aluminium trihydroxide sol for coatings. Materials Letters (32), 25-28.

Hönicke, D., \& Wiessmeier, G. (1996). Heterogeneously catalized reactions in a microreactor. DECHEMA Monographs, Microsystem Technology for Chemical and Biological Microreactors vol. 132 (pp. 93-107).

Koubek, J., Pasek, J., \& Ruzicka, V. (1980). Exploitation of a nonstationary kinetic phenomenon for the elucidation of surface processes in a catalytic reaction. New horizons in catalysis. AmsterdamTokyo: Elsevier-Kodansha, 853-862.

Levenspiel, O. (1972). Chemical reaction engineering. New York: Wiley.

Liauw, M. A., Baerns, M., Broucek, R., Buyevskaya, O. V., Commenge, J.-M., Corriou, J.-P., Gebauer, K., Hefter, H. J., Langer, O.-U., Matlosz, M., Renken, A., Rouge, A., Schenk, R., Steinfelt, N., \& Walter, St. (1999). Periodic Operation in Microchannel Reactors. IMRET 3, Frankfurt/Main.

Moravek, V. (1992). Steady-state and transient kinetics of displacement adsorption and educt inhibition of alcohols on alumina. Journal of Catalysis, 133, 170-178.

Nass, R., \& Schmidt, H. (1990). Synthesis of alumina coating from chelated aluminium alkoxydes. Journal of Non-crystalline Solids, 121, 329-333.

Silveston, P., Hudgins, R. R., \& Renken, A. (1995). Periodic operation of catalytic reactors - introduction and overview. Catalysis Today, 25, 91-112.

Thullie, J., \& Renken, A. (1991). Forced concentration oscillations for catalytic reactions with stop-effect. Chemical Engineering Science, 46, 1083-1088.

Thullie, J., \& Renken, A. (1993). Model discrimination for reactions with a stop-effect. Chemical Engineering Science, 48, 3921-3925.

Wiessmeier, G., Schubert, K., \& Hönicke, D. (1997). Monolytic microreactors possessing regular mesopore systems for the successful performance of heterogeneously catalyzed reactions. First International Conference on Microreacton Technology, Frankfurt, Springer. 